\title{
Mineral Trioxide Aggregate (MTA) vs Calcium Hydroxide in Direct Pulp Capping - Literature Review
}

\author{
Nawras Maher Mostafa ${ }^{1}$ and Shady Ahmed Moussa ${ }^{2 *}$ \\ ${ }^{1} B D S, M S c$, Specialist of Restorative and Advanced Aesthetic Dentistry, PHCC, Qatar. \\ ${ }^{2} B D S, M S c, D D S, M R A C D S$ (DPH), Lecturer and consultant in Pediatric Dentistry and Oral Health Zagazig University, Egypt.
}

*Corresponding author: Shady Ahmed Moussa, Lecturer in Pediatric Dentistry and Oral Health, Zagazig University, Egypt \& Consultant of Pediatric Dentistry and Dental Public Health, PHCC, Qatar.

Received Date: September 24, 2018

Published Date: October 10, 2018

\begin{abstract}
Direct pulp-capping is a treatment for exposed vital pulp involving the placement of a dental material over the exposed area to facilitate both the formation of protective barrier and the maintenance of vital pulp. Direct pulp capping has been used as an alternative approach to the maintenance of vital pulp so that many tooth extractions and root canal treatments could have been avoided through the conservative approach of direct pulp capping. For this purpose different kinds of materials used such as Zinc Oxide Eugenol, Glass Ionomer (GI), Resin Modified Glass Ionomer (RMGI), Adhesive systems, Calcium Hydroxide, Mineral Trioxide Aggregate (MTA) and Bio dentine. The MTA clinically performed more effective than conventional Calcium Hydroxide liner as a direct pulp capping material, showed higher success rate than dycal. MTA easier to use clinically as a direct pulp capping material. MTA provided better long term results more effective than Calcium Hydroxide in maintaining long-term vitality. MAT significantly less toxic, less pulpal inflammations. MTA more predictable than dycal in formation of dentin barrier and superior than Calcium Hydroxide in dentinogenetic process in human pulp. MTA is more effective and superior comparing the Calcium Hydroxide as a direct pulp capping material, showed higher success rate with favorable outcomes in maintaining long term tooth vitality and easier to use in pulp capping. MTA is less toxic, less pulpal inflammation capping compared to Calcium Hydroxide. MTA superior and in dentinogenic process and more predictable hard tissue barrier formation.
\end{abstract}

\section{Introduction}

Direct pulp-capping is a treatment for exposed vital pulp involving the placement of a dental material over the exposed area to facilitate both the formation of protective barrier and the maintenance of vital pulp [1-4]. Direct pulp-capping has been used as an alternative approach to the maintenance of vital pulp so that many tooth extractions and root canal treatments could have been avoided through the conservative approach of direct pulp-capping $[1,5]$. Clinical pulp conditions related to patient symptoms are to be considered before the direct pulp-capping material placement. For evaluating clinical pulp conditions, the most important test is pulp vitality. Pulp capping could be performed on tooth with normal pulp or reversible pulpitis. Percussion, palpation, and periodontal probing test results should be within normal limits. The radiograph should show normal apical tissue. The pulp exposure site should be less than $1 \mathrm{~mm}$ in diameter and stopping pulpal hemorrhage should be prerequisite before direct pulp-capping material placement. If these requirements cannot be satisfied, the pulpcapping procedure is not recommended [1]. There are three causes of vital pulp exposure: caries, mechanical sources and trauma. If pulp exposure occurs before caries is completely removed, it is considered caries exposure. If pulp exposure occurs during the preparation of a cavity without caries, it is called mechanical exposure. Mechanical exposures are typically due to a misadventure during tooth preparation. Traumatic pulp exposure may result from a sports injury when the coronal part of the tooth is chipped. In the event of exposure in vital pulp, direct pulp capping, pulpotomy or pulpectomy could be the treatment choices [1]. According to the American Association of Endodontists (AAE) guide to clinical endodontics, the indications for direct pulp capping are as follows: (1) occurrence of mechanical exposure of a clinically vital and asymptomatic pulp; (2) controlled bleeding at the exposure site; (3) possibility of direct contact of the capping material with the vital pulp tissue after exposure; (4) occurrence of exposure during dental dam isolation of the tooth; (5) maintenance of adequate seal of the coronal restoration; and (6) indication of a possible future endodontic treatment to the patient [7-9]. 


\section{Direct Pulp Capping Materials}

\section{Calcium hydroxide}

Calcium Hydroxide was introduced to the dental profession in 1921 and has been considered the "gold standard" of direct pulp capping materials for several decades $[10,11]$. There are a number of advantages to calcium Hydroxide that have caused it to receive this recognition such as Calcium Hydroxide has high $\mathrm{PH}$ and excellent antibacterial properties [10-13], the calcium Hydroxide has a longterm track record of clinical success as a direct pulp-capping agent in periods of up to 10 years $[8,10]$. Calcium Hydroxide has some disadvantages such as the self-cure formulations are highly soluble and are subject to dissolution over time [10-19] Calcium Hydroxide has no inherent adhesive qualities and provides a poor seal $[1,10]$ Calcium Hydroxide is the appearance of so-called "tunnel defects" in reparative dentin formed underneath Calcium Hydroxide pulp caps $[10,14]$. A tunnel defect has been described as a patency from the site of the exposure through the reparative dentin to the pulp, sometimes with fibroblasts and capillaries present within the defect. However, other researchers have found that the quality of reparative dentin improves as the bridge gets thicker, and that many times, the tunnel defects are not patent with the pulp $[10,15,16]$.

\section{Mechanism of action}

The initial effect of Calcium Hydroxide applied to exposed pulp is the development of a superficial necrosis. Firm necrosis causes slight irritation and stimulates the pulp to defend and repair to form a reparative dentin bridge through cellular differentiation, extracellular matrix secretion and subsequent mineralization .while the formation of a dent in bridge has been believed to be the key for the clinical success of direct pulp-capping $[10,17]$. Traditionally, it has been believed that Calcium Hydroxide's high $\mathrm{pH}$ causes irritation of the pulp tissue, which stimulates repair via some unknown mechanism $[10,18]$. In recent years, this "unknown mechanism" may have been explained by the release of bioactive molecules. It is known that a variety of proteins are incorporated into the dentin matrix during dentinogenetic $[19,20]$ of particular importance to the topic of pulp capping where at least two of these proteins, Bone Morphogenic Protein (BMP) and Transforming Growth Factor-Beta One (TBF- $\beta 1$ ), have demonstrated the ability to stimulate pulp repair $[10,21,22]$. Furthermore, Calcium Hydroxide is known to solubilize these proteins from dentin, lending credence to the release of these bioactive molecules as a significant mediator in pulp repair following pulp capping $[10,23]$.

\section{Mineral Trioxide Aggregate (MTA)}

Mineral Trioxide Aggregate (MTA) has generated considerable interest as a direct pulp-capping agent in recent years. Unset MTA is primarily calcium oxide in the form of tricalcium silicate, dicalcium silicate and tricalcium aluminate. Bismuth oxide is added for radiopacity, MTA is considered a silicate cement rather than an oxide mixture, a so its biocompatibility is due to its reaction products. Interestingly, the primary reaction product of MTA with water is Calcium Hydroxide, and so it is actually the formation of calcium hydroxide that provides MTA's biocompatibility [10,2427] As a result, many of the advantages and potential mechanisms of action for MTA are similar to Calcium Hydroxide, including its antibacterial and biocompatibility properties, high $\mathrm{pH}$, radiopacity and its ability to aid in the release of bioactive dentin matrix proteins. However, an antibacterial effect of MTA is controversial, MTA showed some of the facultative bacteria but no effect on any of the strictly anaerobic bacteria. The antimicrobial activity of MTA may not be as strong as those of traditional Calcium Hydroxidebased cements and sealers. MTA can provide more leakage-proof because of its sealing ability. MTA is suggested to be superior to Calcium Hydroxide due to its uniform and thicker dentin bridge formation, less inflammatory response and less necrosis of pulpal tissues $[1,28]$. There are some differences between MTA and Calcium Hydroxide. First, MTA comes in two colors, white and grey. The grey version is due to the addition of iron. Another significant difference is the fact that MTA provides some seal to tooth structure $[10,29]$. The disadvantages of MTA include long setting times approximately 2 hours and 45 minutes. Setting time of MTA Gray is shorter than that of MTA White. A long setting time may be inconvenient to both dentist and patient, because it requires direct pulp-capping with MTA in two visits: application of MTA in the first visit and seating of the permanent restoration over the sufficiently hardened MTA in the second visit. Moreover, it may increase the risk of bacterial contamination [10,30,31]. Another disadvantage of MTA poor handling "sandy" feeling mixture produced by the coarse particles of Pro Root and water is difficult to be delivered to the required site and hard to condense adequately which can be affected by the particle size and distribution as well as by the shape of the MTA powder $[1,32,33]$. Tooth discoloration has been reported with the use of gray MTA in direct pulp capping and therefore the use of white MTA has generally been recommended in the esthetic zone $[1,34,35]$ However, tooth discoloration associated with white MTA was also described in case reports in endodontic treatments. Tooth color change was reported to be induced by both gray and white MTA. Several factors were reported to contribute to tooth discoloration by white MTA: contamination with blood, contact with sodium hypochlorite, the presence of light and oxygen. The possible involvement of the radio pacifier bismuth oxide in the discoloration is postulated [36-38]. The reason and mechanism of tooth discoloration are not fully understood and remain to be investigated. MTA is very expensive, one gram of MTA powder costs approximately the same as 24 grams of calcium hydroxide base/ catalyst paste, making MTA much less cost effective per use [10].

\section{Bio dentine}

Tricalcium silicate, calcium carbonate, oxide, and zirconium oxide (radio pacifier) in the powder, which is mixed with calcium chloride solution containing modified polycarboxylate instead of water. Both substances in the liquid contribute to shorten setting times (from 10 to $12 \mathrm{~min}$ ). Calcium chloride accelerates the hydration reaction, and polycarboxylate reduces the amount of water required for mixing by providing proper consistency, which also contributes to easy handling of the mixture. Calcium carbonate in the powder is expected to act as a nucleation site in the hydrating mass, enhancing the hydration and leading to faster setting. Bio dentine was reported to have efficacy similar to that of MTA in direct capping over mechanically exposed molar pulps. Complete dentinal bridge formation, an absence of inflammatory pulp response and 
layers of well-arranged odontoblasts and odontoblast-like cells were observed after 6 weeks $[10,39]$.

\section{Adhesive systems}

Adhesive systems were suggested for use as a potential direct pulp-capping agent approximately 12-15 years ago. All components of adhesive systems have been shown to be cytotoxic to pulp cells. The toxic effects of the various components of adhesives are synergistic, especially with increasing duration of contact with the pulp. Toxicity is seen in both multi- and single-component adhesive systems, and the unpolymerized components are more toxic than when the adhesive is well-polymerized [10,40,41].

\section{Glass Ionomer (GI)/Resin-Modified Glass Ionomer (RMGI)}

GI/RMGI is cytotoxic when in direct cell contact. The conventional formulations tend to be less toxic than the resinmodified formulations $[10,42,43]$. This should not be construed as an indictment against the use of GI/RMGI in deep cavities. Because of Glass ionomer's ability to chemically bond to tooth structure, it can prevent the diffusion of potentially toxic materials through dentin to the pulp. Glass ionomer also provides an excellent bacterial seal and shows good biocompatibility when used in close approximation but not in direct contact with the pulp $[10,44,45]$.

\section{Zinc Oxide Eugenol (ZOE)}

ZOE formulations have been used in dentistry for many years as bases, liners, cements and temporary restorative materials. Its use for direct pulp capping is questionable, however. Eugenol is highly cytotoxic. It is known that ZOE releases eugenol in concentrations that are cytotoxic [10,46-48]. ZOE also demonstrates high interfacial leakage. Although it has been noted that this leakage is not important since ZOE can provide a biologic seal due to the eugenol release, it must be kept in mind that eugenol release drops dramatically with time, and it is anticipated that the effectiveness of $\mathrm{ZOE}$ in excluding bacteria is reduced the longer it is in place in the mouth.

\section{The clinical performance of MTA compared to Calcium Hydroxide}

Kierat A et al. [48], evaluated that the usefulness of a new product called MTA used in direct and indirect pulp capping compared with Calcium Hydroxide, which showed $88.2 \%$ of the results were positive after a direct coverage of the pulp using MTA and $86.7 \%$ of positive results were after the application of Calcium Hydroxide. In the case of indirect use of both the MTA and Calcium Hydroxide 100\% positive results were obtained and the MTA showed significantly lower toxicity compared with Calcium Hydroxide. Mente J et al. [49], investigated the treatment outcome of teeth after direct pulp capping, either with MTA or Calcium Hydroxide (controls), they found successful outcome was recorded for $78 \%$ of teeth in the MTA group and for $60 \%$ of teeth in the teeth Calcium Hydroxide group. There was non-significant range ( $P$ $=0.05)$. The teeth that were permanently restored $>$ or $=2$ days after capping had a significantly worse prognosis in both groups $(\mathrm{P}=0.01)$. Same author Mente J [50], aiming to assess treatment outcome of direct pulp capping with MTA versus Calcium Hydroxide. Potential prognostic factors were re-evaluated based on a larger sample size and longer follow-up periods. The overall success rates were $80.5 \%$ of teeth in the MTA group and 59\% of teeth in the Calcium Hydroxide group. There was significantly increased risk of failure for teeth that were directly pulp capped with Calcium Hydroxide compared with MTA $(\mathrm{P}=0.001)$. Teeth were permanently restored $\geq$ 2 days after direct pulp capping had a significantly worse prognosis irrespective of the pulp capping material chosen $(\mathrm{P}=0.004)$ [49]. The study of Leye Benoist $\mathrm{F}$ et al. [50] to assess the effectiveness of MTA used as an indirect pulp-capping material in human molar and premolar teeth. Their results were at 3 months, the clinical success rates of MTA and Calcium Hydroxide were 93\% and 73\%, respectively. At 6 months, the success rate was $89.6 \%$ with MTA, and remained steady at $73 \%$ with Calcium Hydroxide. The mean initial residual dentine thickness was $0.23 \mathrm{~mm}$ and increased by $0.121 \mathrm{~mm}$ with MTA and by $0.136 \mathrm{~mm}$ with Calcium Hydroxide at 3 months. At 6 months, there was an increase of $0.235 \mathrm{~mm}$ with MTA and of $0.221 \mathrm{~mm}$ with Calcium Hydroxide [51]. The randomized clinical trial of Hilton et al. [52], evaluated and compared the success of direct pulp capping in permanent teeth with MTA or Calcium Hydroxide. They found the probability of failure at 24 months was 31.5\% for Calcium Hydroxide vs. 19.7\% for MTA. Zhao Y et al. [53], try to evaluate the volume change of rat root following direct pulp capping with MTA and Calcium Hydroxide-based paste (Vitapex) in randomized control trail, that showed the root volume in the MTA group was significantly smaller than that in the Vitapex group at 2 and 4 weeks after operation $(\mathrm{P}<0.05)$. At the sixth week, there was no significant difference between the MTA group and the Vitapex group ( $\mathrm{P}>0.05)$. The root volume in the MTA group and Vitapex group was significantly larger than that in the model group from the second to sixth week after operation $(\mathrm{P}<0.05)$. The influence of various predictors on healing outcomes after direct pulp capping using either MTA or Calcium Hydroxide as a pulp-dressing agent were evaluated by the retrospective study Çalışkan MK et al. [54]. They found One hundred and fifty-two teeth of 172-capped teeth were available for follow-up, with an overall recall rate of $87.6 \%$ for MTA vs $89.3 \%$ for Calcium Hydroxide. The mean period of followup was $(37.3 \pm 17.2)$ months. Overall success rates of $85.9 \%$ and $77.6 \%$ in the MTA and Calcium Hydroxide groups were observed, respectively. The cumulative success rate of both materials was not statistically different $(\mathrm{P}=0.282)$. The 2-year overall pulp survival was $91.4 \%$, while the 4- and 6-year survival rates were 84 and 65 $\%$, respectively. None of the clinical variables had a considerable influence on the outcome of direct pulp capping ( $p>0.05)$. The randomized control trail of Kundzina R et al. [55], aimed to compare the effectiveness of MTA and a conventional Calcium Hydroxide liner as direct pulp capping materials in adult molars with carious pulpal exposure. They found that at 36 months, the cumulative estimate rate of $85 \%$ for the MTA group and $52 \%$ for the Calcium Hydroxide group $(\mathrm{P}=0.006)$. There was no significant association between the capping material and postoperative pain. The study of (Zhu C et al. [56]) found the success rate of MTA is significantly different than Calcium Hydroxide in direct pulp capping $(\mathrm{P}=0.002)$ and clinically the MTA was superior to calcium hydroxide in direct pulp capping resulting in a lower failure rate. The MTA was found better for direct pulp capping material and showed higher success 
rate clinically and radiographically when compared with Calcium Hydroxide within three months follow up period Sajid M et al. [57]. However, both MTA and Calcium Hydroxide were clinically applicable at the end of 12 months follow up period and there was no significant difference between the protection of the tooth vitality and pulp capping agents at 6 and 12 months $(\mathrm{P}=0.238, \mathrm{P}=0.606$, respectively) according to Vural UK et al. [58].

\section{Pulpal tissue response to MTA compared with calcium hydroxide in direct pulp capping}

MLR Accorinte et al. [59], evaluated the histomorphology response of human dental pulps capped with MTA and Calcium Hydroxide cement in control trail, their results were After 30 and 60 days, teeth were extracted and processed for histologic exam and categorized in a histologic score system. All groups performed well in terms of hard tissue bridge formation, inflammatory response, and other pulpal findings. However, a lower response of Calcium Hydroxide after 30 days was observed for the dentin bridge formation, when compared with MTA after 30 days and MTA after 60 days. Same authors in 2008 were compared the response of human dental pulp capped with MTA and Calcium Hydroxide powder. They found in regard to dentin bridge formation, Calcium Hydroxide after30 days showed a tendency towards superior performance compared to MTA after 30 days ( $>0.05$ ), although the products showed comparable results at day 60. In the item "Inflammation" and "General State of the Pulp" ( $p>0.05$ ), Calcium Hydroxide showed a tendency towards presenting a higher inflammatory response. In the item "Other Pulpal Findings," MTA and Calcium Hydroxide showed equal and excellent performance after 30 and 60 days (p>0.05) [60]. Nair PN et al. [61], investigated the pulp response to the direct pulp capping of healthy human teeth with MTA and Calcium Hydroxide cement (dycal) as control. Their results were the iatrogenic pulpal wounds treated with MTA were mostly free from inflammation after 1 week and became covered with a compact, hard tissue barrier of steadily increasing length and thickness within 3 months following capping. Control teeth treated with Dycal revealed distinctly less consistent formation of a hard tissue barrier that had numerous tunnel defects. The presence of pulpal inflammation up to the longest observation period (3 months) after capping, was a common feature in Dycal specimens. Sawicki L et al. [62], tried to evaluate histological findings in human immature permanent premolars scheduled for extraction for orthodontic reasons, in which mechanical pulp exposures were capped with white ProRoot Mineral Trioxide Aggregate (WMTA) or Calcium Hydroxide and they found no statistically significant differences between WMTA and Calcium hydroxide were found, except for superficial and deep inflammatory cell response $(\mathrm{P}<0.05)$.To evaluate the pulpal response to direct capping with either MTA or Calcium Hydroxide cement in humans, with a focus on dentin bridge formation and dentin sialoprotein and heme oxygenase-1 (HO-1) expression, this study performed in 2008 by Min KS et al. [63] and their results were histologically, $100 \%$ of the MTA group and $60 \%$ of the Calcium Hydroxide group developed dentin bridges. The mean thickness of the dentin bridges observed in the MTA group was statistically greater than that of Calcium Hydroxide group. In addition, DSP and HO-1 were expressed in the odontoblast-like cells and pulp fibroblasts beneath the dentin bridge; furthermore, significantly greater immunostaining was observed in the MTA group than in the Calcium group. Parolia A et al. [64] were investigated the response of human pulp tissue which were mechanically exposed to a new material, Propolis and compare it with two existing and commonly used pulp capping agents (MTA and Dycal) and the results of their study were the differences in inflammatory response and dentine bridge formation of the exposed pulp to the three different materials were statistically non-significant. There was more pulp inflammation in teeth treated with Dycal than with Propolis and MTA on the 15th as well as on the $45^{\text {th }}$ day. Propolis and MTA showed bridge formation in more teeth, and the bridges were in closer proximity to pulp capping material than teeth treated with Dycal on the 45th day. By comparing the response of exposed human pulp to Nano-HA, MTA and Calcium Hydroxide was the purpose of Swarup SJ et al. [65], study at 2014, they found the Nano-HA and MTA produced continuous dentin bridges. Dentin bridge that was formed in MTA group had regular pattern of dentinal tubules, but no tubules were seen in the NanoHA group. Dentin bridge was not observed in Dycal group for the 15 days period in majority of the sample and by 30 days dentin bridge was observed that were both continuous and interrupted in equal number of samples. The initial inflammatory response and necrosis was more with Nano-HA and calcium Hydroxide which reduced with time. The study was done by Nowicka A et al. [66] involved tomographic evaluations of reparative dentin bridge formation after direct pulp capping with Calcium Hydroxide, MTA, Bio dentine (Septodont, Saint Maur des Fosses, France), and Single Bond Universal (3M ESPE, Seefeld, Germany) in human teeth. They found the reparative dentin formed in the calcium hydroxide, MTA, and Bio dentine groups was significantly superior to that formed in the Single Bond Universal group in terms of thickness and volume. The dentin bridges in the Bio dentine group showed the highest average and maximum volumes. The mean density of dentin bridges was the highest in the MTA group and the lowest in the Single Bond Universal group. The clinical and historical findings in human molars directly capped with white ProRoot MTA and Calcium Hydroxide were evaluated by Iwamoto $C$ et al. [67] who found there is no statistically significant differences were found for superficial and deep inflammatory cell response $(\mathrm{P}>0.05)$, presence of a dent in bridge $(\mathrm{P}>0.01)$, and pulp vitality $(\mathrm{P}>0.01)$, between the two materials. The study showed exposure for the teeth in the calcium hydroxide group was statistically significantly smaller than for the white MTA $(\mathrm{P}<0.05)$. The postoperative sensitivity was reported after 7 days between the two materials not significantly different $(\mathrm{P}>0.05)$. The human pulpal response to white and grey mineral trioxide aggregate (WMTA, GMTA) and Dycal as a pulp capping agent where investigated by Eskandarizadeh A et al. [68]. Both types of MTA were recommended as direct pulp capping materials instead of Dycal in this study based on their results that showed the calcified bridge on the teeth capped with GMTA was significantly thicker than Dycal at 30 and 60 days $(\mathrm{P}=0.015$ and $\mathrm{P}=0.002$, respectively and the WMTA calcified bridge formed was significantly thicker calcified bridge than Dycal at 90 days $(\mathrm{P}=0.02)$. The inflammatory response of teeth capped with GMTA significantly less than Dycal after 90 days. Regarding to the calcified 
bridge thickness and pulp inflammatory response to the capping by WMTA and GMTA there were not significantly difference between the two materials $(\mathrm{P}>0.05)$, making them superior on Dycal in direct pulp capping [69].

\section{Conclusion}

The clinical performance of MTA is more effective and superior in comparing to Calcium Hydroxide as a direct pulp capping material and MTA showed higher success rate with favorable outcomes in maintaining long-term tooth vitality. Moreover, the pulpal tissues response of MTA is less toxic, less pulpal inflammation when using as a direct pulp capping compared to Calcium Hydroxide. Furthermore, MTA superior to Calcium Hydroxide in dentinogenic process and more predictable hard tissue barrier formation. Regarding to the performance and success of the MTA compared to Calcium Hydroxide make it the material of choice in direct pulp capping.

\section{References}

1. Komabayashi T, Zhu Q, Eberhart R, Imai Y (2016) Current status of direct pulp-capping materials for permanent teeth. Dent Mater J 35(1): 1-12.

2. Bergenholtz G, Mjör IA, Cotton WR, Hanks CT, Kim S, et al. (1985) The biology of dentin and pulp. Consensus report. J Dent Res 64: 631-633.

3. Pashley DH (1996) Dynamics of the pulpo-dentin complex. Crit Rev Oral Biol Med 7(2): 104-133.

4. Zander HA, Glass RL (1949) The healing of phenolized pulp exposures. 1949. Oral Surg Oral Med Oral Pathol Oral Radiol Endod 100(2 Suppl): S97-S101.

5. Stanley HR (1998) Criteria for standardizing and increasing credibility of direct pulp capping studies. Am J Dent 11 Spec No: S17-S34 .

6. (2004) American Association of Endodontists. Guide to Clinical Endodontics.

7. Costa CA, Mesas AN, Hebling J (2000) Pulp response to direct pulp capping with an adhesive system. Am J Dent 13(2): 81-87.

8. Matsuo T, Nakanishi T, Shimizu H, Ebisu S (1996) A clinical study of direct pulp capping applied to carious exposed pulps. J Endod 22(10): 551-556.

9. Cox CF, Bergenholtz G, Fitzgerald M, Heys DR, Heys RJ, et al. (1982) Capping of the dental pulp mechanically exposed to the oral microflora-a 5-week observation of wound healing in the monkey. J Oral Pathol 11(4): 327-329.

10. Hilton TJ (2009) Keys to Clinical Success with Pulp Capping: A Review of the Literature. Oper Dent 34(5): 615-625.

11. Baume L, Holz J (1981) Long-term clinical assessment of direct pulp capping. Int Dent J 31(4):251-260.

12. Stuart KG, Miller CH, Brown CE Jr, Newton CW (1991) The comparative antimicrobial effect of calcium hydroxide. Oral Surg Oral Med Oral Pathol 72(1): 101-104.

13. Barthel CR, Levin LG, Reisner HM, Trope M (1997) TNF-alpha release in monocytes after exposure to calcium hydroxide treated Escherichia coli LPS. Int Endod J 30(3): 155-159.

14. Prosser HJ, Groffman DM, Wilson AD (1982) The effect of composition on the erosion properties of calcium hydroxide cements. J Dent Res 61(12): 1431-1435.

15. Kitasako Y, Ikeda M, Tagami J (2008) Pulpal responses to bacterial contamination following dentinbridging beneath hard-setting calcium hydroxide and self-etching adhesive resin system. Dent Traumatol 24(2): 201-206.

16. Cox CF, Sübay RK, Ostro E, Suzuki S, Suzuki SH (1996) Tunnel defects in dentin bridges: Their formation following direct pulp capping. Oper Dent 21(1): 4-11.
17. Ulmansky M, Sela J, Sela M (1972) Scanning electron microscopy of calcium hydroxide induced bridges. J Oral Pathol 1(5):244-248.

18. Ferracane J (2001) Materials in Dentistry, Principles and Applications. ( $2^{\text {nd }}$ edn), Williams \& Wilkins, Philadelphia, USA, pp. 63-64.

19. U Schröder (1985) Effects of calcium hydroxide-containing pulp-capping agents on pulp cell migration, proliferation, and differentiation. J Dent Res 64 Spec No: 541-548.

20. Graham L, Cooper PR, Cassidy N, Nor JE, Sloan AJ, et al. (2006) The effect of calcium hydroxide on solubilisation of bio-active dentine matrix components. Biomaterials 27(14): 2865-2873.

21. Duque C, Hebling J, Smith AJ, Giro EM, Oliveira MF, et al. (2006) Reactionary dentinogenesis after applying restorative materials and bioactive dentin matrix molecules as liners in deep cavities prepared in non-human primate teeth. J Oral Rehabil 33(6): 452-461.

22. Zhang W, Walboomers XF, Jansen JA (2008) The formation of tertiary dentin after pulp capping with a calcium phosphate cement, loaded with PLGA microparticles containing TGF- $\beta 1$. J Biomed Mater Res A 85(2):439-444.

23. Smith A (2003) Vitality of the dentin-pulp complex in health and disease: Growth factors as key mediators. J Dent Educ 67 (6): 678-689.

24. Camilleri J, Pitt Ford TR (2006) Mineral trioxide aggregate: A review of the constituents and biological properties of the material. Int Endod J 39(10): 747-754.

\section{Torabinejad M White D US Patent 5,769,638.}

26. Fridland M, Rosado R (2003) Mineral Trioxide aggregate (MTA) solubility and porosity with different water-to-powder ratios. J Endo 29(12): 814-817.

27. Fridland M, Rosado R (2005) MTA solubility: A long term study. J Endod 31(5): 376-379.

28. Camilleri J, Montesin FE, Di Silvio L, Pitt Ford TR (2005) The chemical constitution and biocompatibility of accelerated Portland cement for endodontic use. Int Endod J 38(11): 834-842.

29. Okiji T, Yoshiba K. (2009) Reparative dentinogenesis induced by mineral trioxide aggregate: a review from the biological and physicochemical points of view. Int J Dent 2009: 464280.

30. Ferk Luketić S, Malcić A, Jukić S, Anić I, Segović S, et al. (2008) Coronal microleakage of two root-end filling materials using a polymicrobial marker. J of Endod 34(2): 201-203.

31. Torabinejad M, Hong CU, McDonald F, Pitt Ford TR (1995) Physical and chemical properties of a new root-end filling material. J Endod 21(7): 349-353.

32. Islam I, Chng HK, Yap AU (2006) Comparison of the physical and mechanical properties of MTA and Portland cement. J Endod 32(3): 193197.

33. Aeinehchi M, Eslami B, Ghanbariha M, Saffar AS (2003) Mineral trioxide aggregate (MTA) and calcium hydroxide as pulp-capping agents in human teeth: A preliminary report. Int Endod J 36(3): 225-231.

34. Tomson PL, Grover LM, Lumley PJ, Sloan AJ, Smith AJ, et al. (2007) Dissolution of bio-active dentin matrix components by mineral trioxide aggregate. J Dent 35(8): 636-642.

35. Bogen G, Kim JS, Bakland LK (2008) Direct pulp capping with mineral trioxide aggregate: an observational study. J Am Dent Assoc 139(3): 305315 .

36. Belobrov I, Parashos P (2011) Treatment of tooth discoloration after the use of white mineral trioxide aggregate. J Endod 37(7): 1017-1020.

37. Ioannidis K, Mistakidis I, Beltes P, Karagiannis V (2013) Spectrophotometric analysis of coronal discolouration induced by grey and white MTA. Int Endod J 46(2): 137-144.

38. Camilleri J (2014) Color stability of white mineral trioxide aggregate in contact with hypochlorite solution. J Endod 40(3): 436-440.

39. Nowicka A, Lipski M, Parafiniuk M, Sporniak k-Tutak K, Lichota D, et al. (2013) Response of human dental pulp capped with biodentine and mineral trioxide aggregate. J Endod 39(6): 743-747 
40. Costa CA, Vaerten MA, Edwards CA, Hanks CT (1999) Cytotoxic effects of current dental adhesive systems on immortalized odontoblast cell line MDPC-23. Dent Mater 15(6): 434-441.

41. Ratanasathien S, Wataha JC, Hanks CT, Dennison JB (1995) Cytotoxic interactive effects of dentin bonding. components on mouse fibroblasts. J Dent Res 74(9): 1602-1606.

42. Schmalz G, Schweikl H, Esch J, Hiller KA (1996) Evaluation of a dentin barrier test by cytotoxicity testing of various dental cements. J Endod 22(3): 112-115.

43. Koulaouzidou EA, Papazisis KT, Economides NA, Beltes P, Kortsaris AH (2005) Antiproliferative effect of mineral trioxide aggregate, zinc oxideeugenol cement, and glass-ionomer cement against three fibroblastic cell lines. J Endod 31(1): 44-46.

44. Murray PE, Hafez AA, Windsor LJ, Smith AJ, Cox CF (2002) Comparison of pulp responses following restoration of exposed and non-exposed cavities. J Dent 30(5-6): 213-222.

45. Murray PE, Hafez AA, Smith AJ, Cox CF (2002) Bacterial microleakage and pulp inflammation associated with various restorative materials. Dent Mater 18(6): 470-478.

46. Chang YC, Tai KW, Huang FM, Huang MF (2000) Cytotoxic and nongenotoxic effects of phenolic compounds in human pulp cell cultures. J Endod 26(8): 440-443.

47. Ho YC, Huang FM, Chang YC (2006) Mechanisms of cytotoxicity of eugenol in human osteoblastic cells in vitro. Int Endod J 39(5): 389-393.

48. Kierat A, Laszczyńska M, Kowalska E, Weyna E (2010) Comparison of the influence of mineral trioxide aggregate and calcium hydroxide on dental pulp of permanent teeth in biological treatment and cell cultures. Ann Acad Med Stetin 56(2): 89-96.

49. Mente J, Geletneky B, Ohle M, Koch MJ, Friedrich Ding PG, et al. (2010) Mineral trioxide aggregate or calcium hydroxide direct pulp capping: an analysis of the clinical treatment outcome. J Endod 36(5): 806-813.

50. Mente J, Hufnagel S, Leo M, Michel A, Gehrig H, et al. (2014) Treatment outcome of mineral trioxide aggregate or calcium hydroxide direct pulp capping: long-term results. J Endod 40(11): 1746-1751.

51. Leye Benoist F, Gaye Ndiaye F, Kane AW, Benoist HM, Farge P (2012) Evaluation of mineral trioxide aggregate (MTA) versus calcium hydroxide cement (Dycal $\left({ }^{\circledR}\right)$ ) in the formation of a dentine bridge: a randomised controlled trial. Int Dent J 62(1): 33-39.

52. Hilton TJ, Ferracane JL, Mancl L; Northwest Practice-based Research Collaborative in Evidence-based Dentistry (NWP) (2013) Comparison of $\mathrm{CaOH}$ with MTA for direct pulp capping: a PBRN randomized clinical trial. J Dent Res 92 (7 Suppl): 16S-22S.

53. Zhao Y, Jin A, Gao P, Mitsuko I (2013) An experimental study on mineral triozide aggregate and calcium hydroxide-based paste applied to direct pulp capping in rat. Zhonghua Kou Qiang Yi Xue Za Zhi 48(8): 494-498.

54. Çalışkan MK, Güneri P (2017) Prognostic factors in direct pulp capping with mineral trioxide aggregate or calcium hydroxide: 2- to 6-year follow-up. Clin Oral Investig 21(1): 357-367.

55. Kundzina R, Stangvaltaite L, Eriksen HM, Kerosuo E (2017) Capping carious exposures in adults: a randomized controlled trial investigating mineral trioxide aggregate versus calcium hydroxide. Int Endod J 50(10): 924-932.
56.Zhu C, Ju B, Ni R (2015) Clinical outcome of direct pulp capping with MTA or calcium hydroxide: a systematic review and meta-analysis. Int ] Clin Exp Med 8(10): 17055-17060.

57. Mustafa S, Jamil, Sajjid I, Munir B, Kouser R (2016) Comparison of effectiveness of mineral trioxide aggregate ( $\mathrm{mta}$ ) and calcium hydroxide as direct pulp capping materials. Pakistan Oral \& Dental J 36(2): 319322.

58. Vural UK, Kiremitçi A, Gökalp S (2017) Clinical Assessment of Mineral Trioxide Aggregate in the Treatment of Deep Carious Lesions. Niger J Clin Pract 20(5): 600-604.

59. Accorinte ML, Loguercio AD, Reis A, Carneiro E, Grande RH, et al. (2008) Response of human dental pulp capped with MTA and calcium hydroxide powder. Oper Dent 33(5): 488-495

60. Accorinte Mde L, Holland R, Reis A, Bortoluzzi MC, Murata SS, et al. (2008) Evaluation of mineral trioxide aggregate and calcium hydroxide cement as pulp-capping agents in human teeth. J Endod 34(1): 1-6.

61. Nair PN, Duncan HF, Pitt Ford TR, Luder HU (2008) Histological, ultrastructural and quantitative investigations on the response of healthy human pulps to experimental capping with Mineral Trioxide Aggregate: a randomized controlled trial. Int Endod J 41(2): 128-150.

62. Sawicki L, Pameijer CH, Emerich K, Adamowicz-Klepalska B (2008) Histological evaluation of mineral trioxide aggregate and calcium hydroxide in direct pulp capping of human immature permanent teeth. Am J Dent 21(4): 262-266.

63. Min KS, Park HJ, Lee SK, Park SH, Hong CU, et al. Effect of mineral trioxide aggregate on dentin bridge formation and expression of dentin sialoprotein and heme oxygenase-1 in human dental pulp. J Endod 34(6): 666-670.

64. Parolia A, Kundabala M, Rao NN, Acharya SR, Agrawal P, et al. (2010) A comparative histological analysis of human pulp following direct pulp capping with Propolis, mineral trioxide aggregate and Dycal. Aust Dent J 55(1): 59-64.

65. Swarup SJ, Rao A, Boaz K, Srikant N, Shenoy R (2014) Pulpal response to nano hydroxyapatite, mineral trioxide aggregate and calcium hydroxide when used as a direct pulp capping agent: an in vivo study. J Clin Pediatr Dent 38(3): 201-206

66. Nowicka A, Wilk G, Lipski M, Kołecki J, Buczkowska-Radlińska J (2015) Tomographic Evaluation of Reparative Dentin Formation after Direct Pulp Capping with $\mathrm{Ca}(\mathrm{OH})_{2}$, MTA, Biodentine, and Dentin Bonding System in Human Teeth. J Endod 41(8): 1234-1240.

67. Iwamoto CE, Adachi E, Pameijer CH, Barnes D, Romberg EE, et al. (2006) Clinical and histological evaluation of white ProRoot MTA in direct pulp capping. Am J Dent 19(2): 85-90.

68. Eskandarizadeh A, Shahpasandzadeh MH, Shahpasandzadeh M, Torabi M, Parirokh M (2011) A comparative study on dental pulp response to calcium hydroxide, white and grey mineral trioxide aggregate as pulp capping agents. J Conserv Dent 14(4): 351-355.

69. Torabinejad M, Hong CU, Pitt Ford TR, Kettering JD (1995) Cytotoxicity of four root end filling materials. J Endod 21(10): 489-492. 